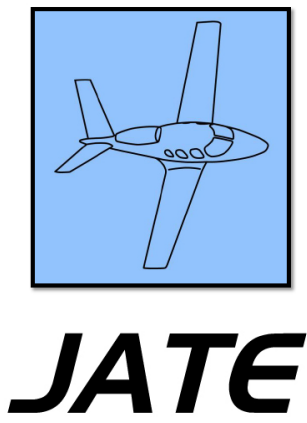

Journal of Aviation Technology and Engineering 8:1 (2018) 20-30

\title{
Collaborative Product-Service Approach to Aviation Maintenance, Repair, and Overhaul. Part I: Quantitative Model
}

\author{
Cassio Dias Goncalves and Michael Kokkolaras
}

Department of Mechanical Engineering, McGill University

\begin{abstract}
This two-part paper proposes a new collaborative approach to airframe maintenance, repair, and overhaul (MRO). A quantitative model is introduced in Part I to represent the business relationships between original equipment manufacturers (OEMs) and MRO enterprises. In Part II, the presented model is used to assess potential financial benefits obtained by each of these stakeholders as a result of the collaboration.

The quantitative model is built to capture the main dependencies between an independent MRO enterprise operating in South America and its interactions with three major airframe OEMs. Interviews were conducted with MRO and OEM professionals to identify the most impactful operational resources on MRO activities. Stakeholders with different characteristics in terms of production capacity, annual revenue, fleet size, and age are considered in numerical studies to quantify the viability of the proposed collaborative business model in different scenarios.

The obtained results show that optimal investment levels must be determined for each stakeholder to ensure the viability of the proposed collaborative business model, confirming the need for a quantitative method to aid service designers making decisions.

The novel collaborative model contributes to the relatively scarce literature on the topic, and promotes effective and structured collaboration between OEMs and MRO enterprises aiming at delivering higher added value to end customers (operators).
\end{abstract}

Keywords: airframe maintenance, repair and overhaul, product-service design, collaborative business model

\section{Introduction}

An increasing demand for independent aviation maintenance, repair, and overhaul (MRO) services has been perceived over the last few years (Rosenberg, 2004). As a result of this trend, aircraft owners and operators started to outsource heavy maintenance activities and large MRO companies emerged, such as Singapore Technologies Aerospace, AAR Corp, Timco Aviation Services, Lufthansa Technik, Haeco Group, and others (Tegtmeier, 2013). Along that trend, smaller independent service providers appeared around the globe, quickly accounting for $80 \%$ of the MRO market (PIPAME, 2010).

However, this new outsourced maintenance market implies some challenges to these independent MRO companies. They usually serve different airlines with several models of aircrafts, and hence are often compelled to heavily invest in resources such as equipment, spare parts, and training in order to attend a variety of aircraft models at high service levels. Often, the acquisition of these resources does not represent an attractive investment, thus entailing a direct impact on financial results. 
For instance, service providers frequently see themselves as forced to have some special equipment which is only required to perform very specific maintenance tasks for a particular aircraft model. Such tasks have a low frequency of occurrence; as a consequence, resources are underutilized, resulting to low return on investment. Special tools rental options are available in the market; however, they do not always constitute a timely and reliable solution. This situation imposes significant financial challenges to MRO firms. In summary: at one end operators rely on MRO companies to provide them with high-level maintenance services, while at the other end MRO companies may struggle financially to keep their maintenance capacity broad enough to support a wide range of aircraft.

Airframe original equipment manufacturers (OEMs) have also been requested increasingly by operators to provide better in-service support. However, an OEM-owned, worldwide customer support structure that is capable of offering full maintenance services is economically infeasible. Moreover, it has been observed that existing business practices related to airframe maintenance services may result in predatory competition among stakeholders (Goncalves \& Kokkolaras, 2017). Specifically, due to the low level of inservice support offered by airframe manufacturers and maintenance providers over the years, many operators (such as commercial airlines or air force organizations) have developed their own fleet maintenance stations. However, cost effectiveness is a big challenge, since maintenance is not their core business. Some operators, in order to justify the investments made in large maintenance structures, started to provide services to smaller operators, adding a new challenge to the maintenance market, as they were then competing with OEM service centers and independent maintenance providers (Vieira \& Loures, 2016).

This research work proposes the consideration of a new business strategy as a more rational alternative for this paradoxical scenario, where manufacturers compete with their own customers. The new strategy suggests that OEMs and MRO companies should align their business interests to foster a collaborative environment that will benefit them both. Given that the operational life of an aircraft can be more than 50 years, there is a significant opportunity for aviation OEMs and MRO companies to profit from a collaborative product-service system (PSS) business model that can provide operational excellence by supporting the product during its in-service life (Goncalves \& Kokkolaras, 2015). By creating a sustainable partnership, maintenance providers and manufacturers could offer higher service levels to operators. The business relations between these two players could be designed under the approach of cooperation to maximize availability of operational resources at these maintenance centers. Having the right resources available when required, MRO companies would become a more effective maintenance option for operators. In other words, the greater the availability of these resources for the
MRO company during maintenance activities, the more efficient will be the execution of the service, resulting in reduced maintenance turnaround time (TAT), thus additional value to operators.

Aiming at identifying the most relevant resources for MRO companies' efficient operations, this research has conducted interviews with MRO and OEM professionals from Brazil, Spain, Argentina, and Chile (where the interviewees were an engineering/planning manager, a quality and regulations manager with more than 30 years of experience in the international MRO sector, a maintenance manager, an experienced MRO specialist, a chief executive officer of an MRO business in South America, and a maintenance supervisor with more than 30 years of MRO experience), and the main question was: what are the most impactful operational resources for MRO activities? There was consensus among the interviewees that the four types of operational resources that have the highest impact on the TAT are: product data; spare parts; tooling and equipment; and qualified technical personnel.

Therefore, the collaboration approach proposed herein suggests the thesis that OEMs and MRO firms should develop a win-win partnership where these companies could mutually cooperate by exchanging those critical resources, as depicted in Figure 1.

As mentioned above, product data, spare parts, tooling, equipment, and training are essential resources for MRO activities. Therefore, an OEM could contribute to increase availability of these resources by enabling the partner maintenance providers to have access to product data, or sharing spare parts and equipment, or even offering special conditions for technical training. On the other hand, OEMs are highly interested in the in-service data collected by MRO firms over long periods of time for a variety of aircraft. This would provide valuable information and knowledge to an OEM's product design process and thus increase product reliability while reducing costs related to re-design and warranty claims.

In summary, this paper proposes a collaborative PSS approach to airframe in-service support. A quantitative model is developed to map the main business relationships between the OEM, the MRO enterprise, and the operator. This model enables engineers to perform quantitative analysis to assess financial feasibility as well as value added of different collaboration business models. Due to paper length limitations, numerical results are presented in the companion of this paper (Part II).

\section{The Proposed Collaboration Model}

One of the key variables of this quantitative model is the TAT, which refers to the elapsed time of a maintenance check. In the context of this study, when a TAT increase is mentioned, it refers to the delay to the planned maintenance service schedule. A reduced TAT corresponds to added 


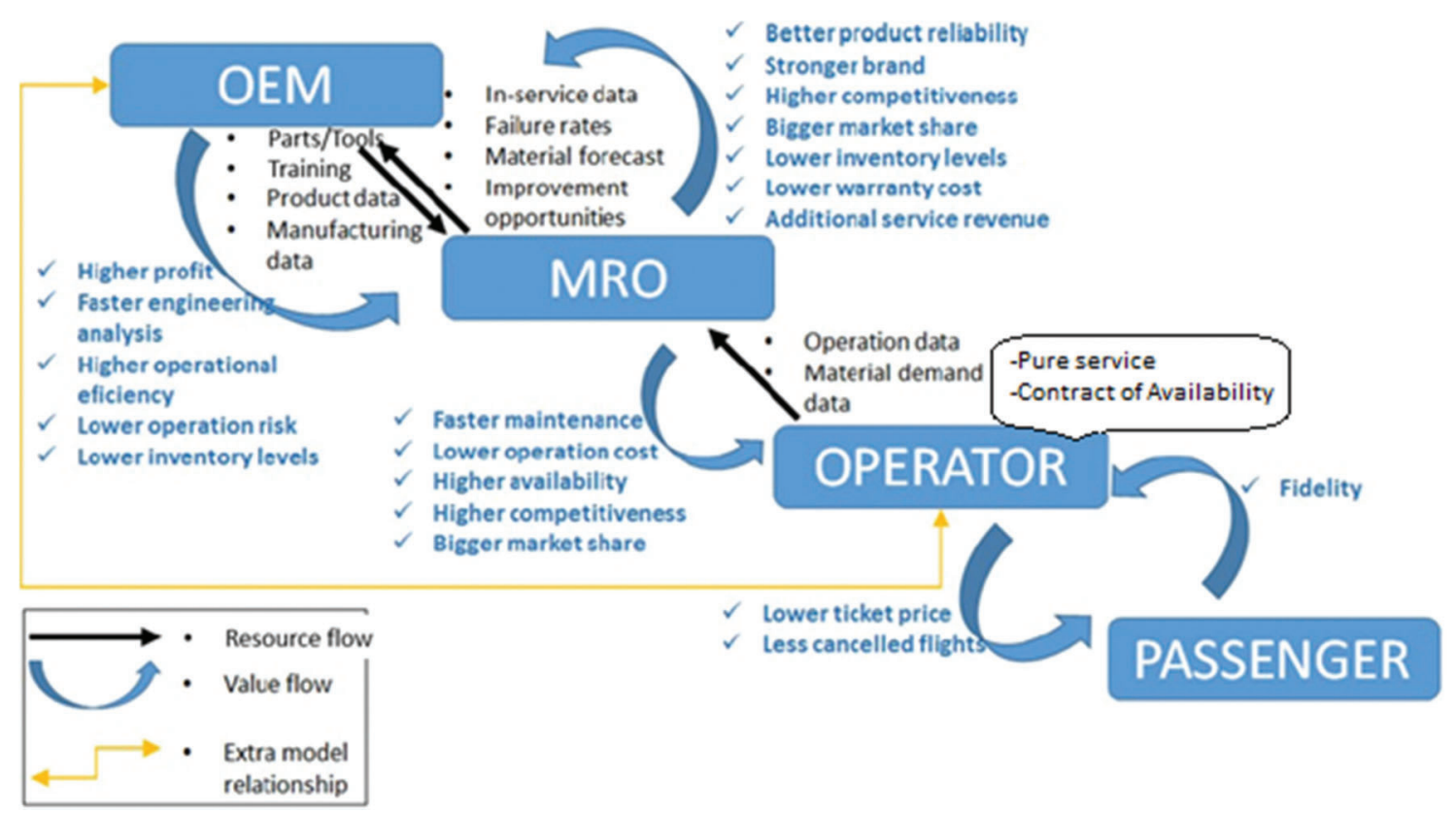

Figure 1. Proposed value and data flow in OEM and MRO collaboration.

value to operators. According to the Federal Aviation Administration (2013), one of the three main reasons that operators outsource maintenance activities to MRO concerns is the reduced TAT to complete the service, since these maintenance providers have higher level of specialization.

In that sense, if TAT reduction means value added to operators, then it can be assumed that reducing the risk of TAT increase is a value-added objective within an MRO business. Conceptually, the risk of TAT increase is inversely proportional to the level of resource availability. Indeed, the shortage of any of the above resources implies risk of TAT increase, so the researchers propose to capture the relation between TAT increase and resource availability as

$$
E T I_{\text {res }_{i}}=T I_{\text {res }_{i_{\text {avg }}}} \times I G_{\text {res }_{i}}
$$

where $E T T^{r e s_{i}}$ is the expected TAT increase (days) due to lack of resource res ${ }^{i} ; T I_{\text {res }_{\text {iavg }}}$ is the average TAT increase (days) in the case of resource res $^{i}$ not being available when required; and IGres $^{i}$ is the investment gap (\%) that represents the probability of lacking res ${ }^{i}$. It is defined as

$$
I G_{r e s_{i}}=\frac{\left(I R_{\text {res }_{i}}-I S O E M_{\text {res }_{i}}-I M R O_{\text {res }_{i}}\right)}{I R_{r e s_{i}}},
$$

where $I R^{r e s}$ is the required investment in resource $r e s^{i}$ in order to completely mitigate the risk of its unavailability. The amount of required investment needs to be set as a parameter in the mathematical model and will usually depend on the MRO company's production capacity. It can either be obtained with an MRO expert or from the MRO company's historical data. ISOEMres is the investment shared by the OEM and $I M R O^{r e s_{i}}$ represents the actual investment in res $^{i}$ made by the
MRO company. The value of $T I_{\text {res }_{i v g}}$ is also a parameter to be set in the model and it can also be estimated by an MRO expert, obtained from an MRO company's historical data, or even calculated by using the program evaluation and review technique/critical path method (PERT/CPM) (Darci, 2004). Most MRO companies adopt specific software based on PERT/CPM to plan and schedule maintenance tasks with the objective of better managing and reducing TAT through critical path analysis. By so doing, MRO companies are able to plan the usage of resources, estimate TAT for each aircraft shop visit in a more precise manner, and also better monitor the progress of the maintenance tasks during the project execution. In addition, this type of technique also enables analysis of impacts on service schedule caused by deviations such as lack of required resources or any other technical problem encountered during the execution of the maintenance activities. Figure 2 conceptually illustrates the main phases of an aircraft heavy maintenance check: in Phase 1 the aircraft is completely cleaned and has all its access panels opened for inspection; Phase 2 is when all the scheduled visual inspections, functional tests, operational tests, and other nondestructive tests are performed, and therefore it can be said that this is the phase where all the aircraft discrepancies are identified; in Phase 3, the discrepancies previously identified are corrected by means of parts replacements or repairs. Usually, the more significant TAT delays originate from Phase 3 activities, where the majority of the unplanned resource demand occurs; at last, once all the aircraft discrepancies are resolved, then the aircraft enters into Phase 4 for final tests and delivery preparation.

Within the context of this study, the TAT increase caused by unavailability of required resources is considered to happen in the "rectification phase" of the aircraft heavy maintenance, as shown in Figure 2. Therefore, the value of 


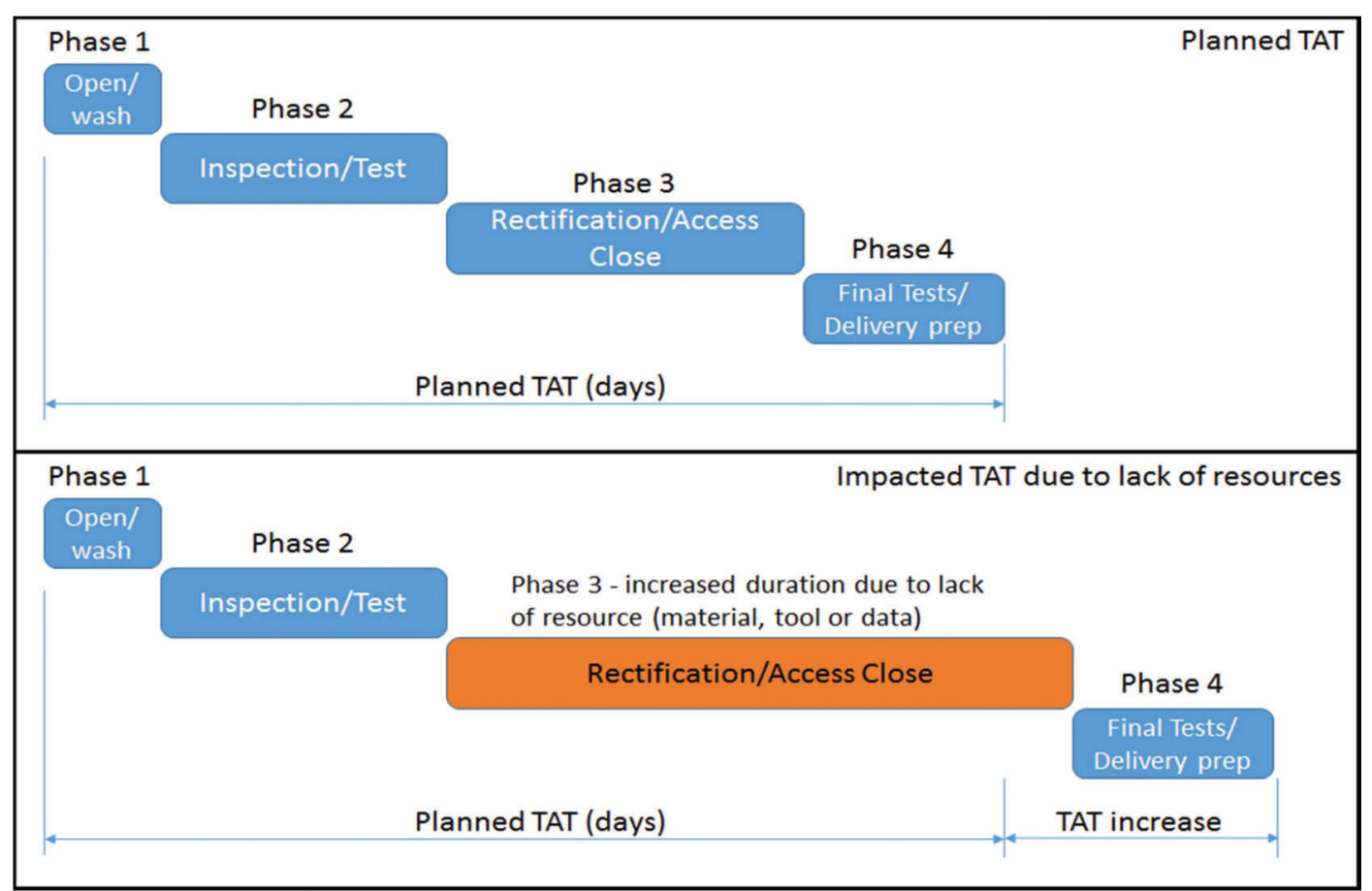

Figure 2. Conceptual scheme of the impact on TAT due to lack of resources.

$T I_{\text {res }_{i a v g}}$ can be obtained by taking the difference between the acquisition time of the resource (including procurement time, import time, transportation, and utilization) and the time originally planned for Phase 3 . The average acquisition time of the unplanned resource can be estimated by an MRO expert or even obtained from the purchasing department's historical data. That type of information (also called logistic lead times) is usually recorded and stored in material and resources planning systems. The planned time of each phase is estimated by the MRO expert and depends on the type of maintenance check as well as on the type of aircraft.

To facilitate the reader's comprehension of the rationale adopted to construct the proposed model, the following summary is given:

a. The amount of investments made by OEM or MRO company in any of the required resources (i.e., product data, spare parts, tooling, or training) represents the level of financial collaboration from each company in the PSS.

b. The individual investments in resources correspond to the input variables.

c. The higher the total investments, the more maintenance capacity the MRO company will offer; therefore, the shorter will be the aircraft's downtime during heavy maintenance, meaning higher savings to operators.

d. Every investment made by the OEM in resources required for the PSS represents a positive impact on the MRO company's gross profit.

e. The more in-service data the MRO company shares with the OEM, the higher is the OEM's savings with inventory reduction due to increased demand forecast capacity.

f. The impact on MRO company's and OEM's gross profit are output variables as well as the total operator savings.

g. The more heavy the checks performed by the MRO company, the more in-service data are generated. The number of heavy checks per year performed by the MRO company is a PSS configuration parameter.

h. The operator's fleet size and number of flight hours per year per aircraft are also PSS configuration parameters. The larger the fleet size and the greater the number of flown hours, the more savings the operator can accumulate throughout the year.

i. All formulas and linear models presented in this paper are developed and proposed as first principles by the authors.

Given the overall rationale as the foundation for the proposed quantitative approach, each resource is taken into consideration by the model to capture the effects of variations of its availability on financial results to stakeholders as well as on TAT to operators.

\section{Spare Parts and Tooling}

Spare parts and tools availability is one of the key factors for ensuring continuous operations in an MRO company. The lack of those resources when needed during maintenance activities directly implies delays of the TAT to operators. In the scope of this research, the types of spare 
parts are classified as follows (Goncalves \& Kokkolaras, 2017): consumable; light expendable; heavy expendable; and rotable. The main types of tools and equipment considered herein are: nondestructive inspection equipment; hydraulic carts; special tools; test sets; and special jigs.

The estimated TAT increase caused by the lack of these resources during maintenance services will be individually calculated for each of the above types, by applying Equation (1). The values of parameters such as $T I_{\text {res }_{\text {avg }}}$ and $I R_{r e s_{i}}$ are chosen depending on the type of resource. For instance, $T I_{\text {hep }_{\text {avg }}}$ is the average TAT increase (days) resulting from the unavailability of a heavy expendable part. In most of the cases, lacking a required heavy expendable when needed during maintenance check execution implies a significant TAT delay, caused by the usually longer procurement time for that type of part. Assuming that during a maintenance check the demand for most of the heavy expendable parts will be known only after the inspection phase (see Figure 2 for reference on maintenance check phases), and heavy expendables usually require heavier subsequent maintenance activities such as heat treatment, shot peening, machining, complex installation, and extensive access closing, then the impact of $T I_{\text {hep avg }}$ on the rectification phase can also be calculated by using the PERT/CPM technique. The logistics lead times and maintenance tasks durations can be either estimated by experts or obtained from statistical data for that type of spare part.

The investment gap related to heavy expendable parts $I G_{\text {hep }}$ is

$$
I G_{\text {hep }}=\frac{\left(I R_{\text {hep }}-I S O E M_{\text {hep }}-I M R O_{h e p}\right)}{I R_{\text {hep }}},
$$

where $I R_{\text {hep }}$ is the required investment amount in heavy expendable parts in order to mitigate the risk of unavailability of that resource. That variable also represents a model's parameter which shall be set as per MRO company's production capacity (production scale and types of aircrafts). It can be either estimated by an expert or obtained from historical data. ISOEM hep is the investment shared by the OEM and $I M R O_{\text {hep }}$ is the actual investment in heavy expendable parts made by the MRO company.

The TAT increases resulting from unavailability of other types of spare parts or tools are similarly calculated using Equations (1) and (2). Each type will present specific parameters $T I_{\text {resi }_{\text {avg }}}$ and $I R_{\text {res }_{i}}$ as per the individual characteristics of each resource. For example, $T I_{c_{\text {avg }}}$ is the average TAT increase (days) resulting from the unavailability of a consumable part. It can be obtained by taking the difference between the estimated acquisition time of consumable parts and the time originally planned for Phase 3 (cf. Figure 2). In most cases, if the MRO company lacks a required consumable, the delay in TAT should not be significant since the procurement and acquisition time for this type of material is short and it can usually be bought locally.
In addition, consumables usually do not require long subsequent activities, just simple tasks such as access panel closing. The value of $I R_{c p}$ represents the investment required in consumable parts and is related to the MRO company's production capacity (i.e., production scale and types of aircrafts produced): the higher the production capacity, the larger the inventory required, and the higher the investment needed. It can be either estimated by an expert or obtained from historical data.

In summary, the rationale used to formulate the TAT increase as a function of the resources availability level is as follows: the smaller the investment gap, the lower the risk of TAT delay. Thus, hypothetically, if an MRO company has unlimited resources, then the risk of TAT delays would be zero. However, as a matter of fact, enterprises usually face resource limitations imposed by budgetary constraints. Having large inventories of spare parts and tooling requires high investments for an MRO company, which most of the time is not economically sustainable. Therefore, the concept considered by the proposed model is that OEM and MRO company should split these investments to develop a financially feasible collaboration. This mathematical model proposes to evaluate the financial feasibility of the collaboration by analyzing the impact on gross profit for both companies generated by the related investments.

For instance, if an OEM invests in an MRO company by providing resources such as spare parts and tooling to that maintenance provider, this investment would cause a negative impact on the OEM's gross profit. On the other hand, that same investment would lead to a positive impact on the MRO company's gross profit. The opposite effect would occur when the MRO company shares its resources with the OEM. Hence, this model proposes to calculate the final balance of impact on gross profit to use it as a financial indicator of the PSS's economic viability. The impact on gross profit was selected as an indicator due to its direct relation to operational costs, enabling assessment of the company's efficiency at labor and supplies. In accounting, gross profit, also known as gross margin, is a company's revenue minus the cost of making a product or providing a service, before deducting indirect fixed costs like office expenses, rent, administrative costs, and taxation. The annual impact on an OEM's gross profit, resulting from the investment in any of the previously described resources $r e s_{i}$ made on MRO, is given by

$$
I G P_{O E M_{r e s}}=\frac{O C_{O E M_{r e s}}}{G P_{O E M}}
$$

where $G P_{O E M}$ is the OEM's gross profit and $O C_{O E M \text { res }_{i}}$ is the annual opportunity cost of the investment in that resource made by the OEM in MRO; it is formulated as

$$
O C_{O E M_{\text {res }}}=-\left(\sum_{i=1}^{n} \text { OEMI }_{\text {res }_{i}}\right) \times I R,
$$

where $O E M I_{\text {res }}$ is the monetary amount invested in res $_{i}$ by the OEM in the MRO company and $I R$ is the interest rate. 
The positive impact on the MRO company's gross profit due to investment in res $_{i}$ received from the OEM is

$$
I G P_{M R O_{r e s i}}=\frac{\left(-O C_{O E M_{r s s_{i}}}-O C_{M R O_{r e s i}}\right)}{G P_{M R O}},
$$

where $G P_{M R O}$ is the MRO company's gross profit and $O C_{\text {MROres }}$ is the annual opportunity cost of the investment in $r e s_{i}$ made by the MRO company, given by

$$
O C_{M R O_{\text {res }}}=\left(\sum_{i=1}^{n} M \text { MRI }_{\text {res }}\right) \times I R,
$$

where $M R O I_{r e s}$ is the investment in $r e s_{i}$ made by the MRO company.

\section{Technical Data}

During the development of an aircraft, as part of its certification requirements, the OEM must produce several types of technical publications. The aircraft maintenance manual is one of the most important publications to MRO companies, as it provides detailed technical instructions for proper performance of the maintenance tasks. The maintenance providers also rely on other important product data to ensure efficiency of their operations, reducing cycle time to resolve technical problems found during maintenance services execution. Agility to resolve technical problems results in shorter aircraft downtime, meaning value to operators. The main types of product data considered in this research work are: 1) installation drawings; 2) fabrication drawings; 3) component maintenance manuals; and 4) service bulletins.

On the other hand, during aircraft shop visits, MRO firms collect significant amounts of in-service data such as maintenance and pilot reports; maintenance actions; troubleshooting reports; or component shop reports. These data represent valuable information to OEMs and can be used to identify weaknesses of their products, thus promoting improvement opportunities related to the product reliability and consequently enhanced maintenance programs (Canaday, 2016).

\section{Product Data}

Technical product data produced by OEMs are usually sold to MRO firms through annual subscriptions, where the more the access to data required, the higher the price. Product data are also an important resource for MRO operations, as quick access to them may represent on-time technical problems resolution. In contrast, the lack of this type of data during a maintenance event creates the risk of TAT increase. The TAT increase resulting from product data unavailability is formulated for each type of data and its relationship with spare parts resources as follows:

$$
E T I_{p d_{i}}=\left(L T_{p d_{i}} \times I G_{p d_{i}}\right)+E T I_{r^{2} s_{i}},
$$

where $E T I_{p d_{i}}$ is the estimated TAT increase caused by the unavailability of one of the four required product data resources when needed. $L T_{p d_{i}}$ is the average acquisition lead time (days) of the related product data resource during maintenance activities. This value can be estimated by senior purchasing department personnel or obtained from historical data. ETI res $_{i}$ is the previously estimated TAT increase due to lack of that product's related spare part. For example, in most cases an installation drawing will call up light expendable parts such as attaching parts, thus the expected procurement and logistics time for acquisition of those parts must compose the referred function. Additionally, fabrication drawings relate to heavy expendable parts, component maintenance manuals may call up rotable parts, and service bulletins may also relate to light expendable parts. $I G_{p d_{i}}$ is the investment gap (\%) related to that product data resource and it represents the probability of lacking this resource during maintenance activities. It is calculated as

$$
I G_{p d_{i}}=\frac{\left(I R_{p d_{i}}-I S O E M_{p d_{i}}-I M R O_{p d_{i}}\right)}{I R_{p d_{i}}},
$$

where $I R_{p d_{i}}$ is the investment required by the MRO company for acquisition of those specific product data in order to have prompt availability of that resource when needed. ISOEM $M_{p d_{i}}$ is the investment shared by the OEM (by granting free limited access to that type of product data for partner MRO companies) and $I M R O_{p d_{i}}$ is the actual investment in subscriptions of that product data resource made by the MRO company.

As previously mentioned, in usual commercial conditions OEMs sell product data to MRO companies by means of annual subscriptions; therefore when sharing this resource with MRO companies, as proposed in this work, OEMs would lose revenue. That negative impact on an OEM's gross profit $I G P_{O E M_{p d}}$ can be assessed by the proposed collaboration business model. It is calculated as

$$
I G P_{O E M_{p d}}=\sum_{i=1}^{n} I G P_{O E M_{p d i}},
$$

where $I G P_{O E M_{p d_{i}}}$ is the negative impact (\%) on the OEM's gross profit resulting from the revenue reduction with technical data subscriptions caused by the concession of free limited access to the referred product data for the MRO company. It is calculated as the ratio between the investment in the specific product data made by the OEM $O E M I_{p d_{i}}$ to support the MRO company and the OEM's gross profit $G P_{O E M}$ :

$$
I G P_{O E M_{p d_{i}}}=-\frac{O E M I_{p d_{i}}}{G P_{O E M}} .
$$

On the other hand, OEMs sharing their product data with MRO companies creates a positive impact on MRO firms' gross profit since they are reducing expenditures related to product data subscriptions. This positive impact on MRO firms' gross profit is 


$$
I G P_{M R O} O_{d}=\sum_{i=1}^{n} I G P_{M R O_{p d i}} .
$$

It is calculated based on the ratio between the MRO firm's investment in product data $M R O I_{p d i}$ and the MRO firm's gross profit $G P_{M R O}$ :

$$
I G P_{M R O_{p d_{i}}}=\frac{\left(-M R O I_{p d_{i}}+O E M I_{p d_{i}}\right)}{G P_{M R O}} .
$$

\section{In-Service Data}

In the MRO growing market, the increasing amounts of in-service data (collected from maintenance reports produced during aircraft shop visits) have attracted the attention of OEMs since this information can be used to perform statistical analysis and identification of weaknesses of a product (Rosenberg, 2004). Product reliability can be improved based on that outcome, enabling increased maintenance intervals, fewer shop visits, and consequently less interruption of aircraft operations. OEMs can offer increased fleet dispatch reliability, which is an important quality indicator as well as a strong selling point. Boeing has been making significant improvements in maintenance programs by applying statistical analysis on in-service data. From 1997 to 2011 Boeing optimized its B737-NG airplane's maintenance program, being able to extend 1000 flight hours in hangar scheduled maintenance intervals every four years, which is on average 250 flight hours per year (McLoughlin, Doulatshahi, \& Onorati, 2011). Based on Boeing's data, this paper proposes to model the relation between the amount of in-service data available to OEMs and the resulting maintenance interval increase as follows:

$$
M I I_{\text {year }}=N R A_{\text {year }} \times M I I R_{F H / r e p},
$$

where $M I I_{\text {year }}$ is the heavy maintenance interval increase (flight hours) per year promoted by an OEM for a specific aircraft model and $N R A_{\text {year }}$ represents the annual number of maintenance reports available from MRO companies to OEMs, calculated as

$$
N R A_{\text {year }}=N R_{A C / \text { year }} \times N H C_{\text {year }},
$$

where $N R_{A C / y e a r}$ is a parameter representing the estimated number of maintenance reports generated by one aircraft in a one-year time span. This number can be estimated by an MRO expert or obtained from statistical analysis using previous heavy checks data. The parameter $N H C_{\text {year }}$ represents the number of planned heavy checks per year to be performed by the MRO company. This value shall be defined according to the production capacity of the MRO company. The maintenance interval increase ratio $M I I R_{F H / r e p}$ expresses the maintenance interval increase (flight hours) produced by one maintenance report, and is calculated as

$$
M I I R_{F H / \text { rep }}=\frac{250}{\left(240 \times N R_{A C / \text { year }}\right)} .
$$

Considering Boeing's publication (McLoughlin et al., 2011), which reports 1000 flight hours increase of maintenance intervals in four years, this work proposes the use of the constant 250 in Equation (16), corresponding to the maximum annual maintenance interval increase that OEMs would be able to produce. In addition, the constant 240 represents the reasonable number of aircrafts per year that would be required to produce sufficient in-service data to enable statistical analysis to be translated into conclusive maintenance interval increase. This value is defined based on an Airbus study that uses in-service data produced by 240 aircrafts (A320 model) operated by EasyJet over a time period of four years (Canaday, 2016). The model proposed herein does not take into account the financial benefit that OEMs would obtain as a result of their sales increase for offering a more reliable product to the market. More reliable airplanes enable stretched maintenance intervals, which certainly promotes economic advantages to aircraft operators. In fact, Lee, Ma, Thimm, and Verstraeten (2008) mention a case where a European airline achieved a $25 \%$ reduction in its direct maintenance cost by reusing in-service data. Therefore, the total annual savings that OEMs could promote to operators by using in-service data from MRO companies are formulated as the sum of the annual savings due to direct maintenance cost reduction and the annual savings resulting from increased heavy maintenance intervals:

$$
T O p S_{i s d a t a}=O p S_{d m c_{r e d}}+O p S_{m i_{i m r}} .
$$

Based on Lee et al. (2008), Ops $s_{\text {dmcred }}$ is calculated as $25 \%$ of the total direct maintenance cost:

$$
O p S_{d m c_{r e d}}=0.25 \times\left(\frac{O F S}{240}\right) \times E M C_{p e r A C} \times O F S,
$$

where OFS is the operator's fleet size. The number 240 is the ideal fleet size, as per an Airbus study (Canaday, 2016), so that number is used as the basis for the assumption that 240 aircrafts would produce sufficient data to promote conclusive statistical analysis and enable maintenance cost reduction of the order of $25 \%$. $E M C_{\text {perAC }}$ corresponds to the estimated annual maintenance cost per aircraft and is given by

$$
E M C_{\text {per } A C}=F H Y_{\text {per } A C} \times F H C,
$$

where $F H Y_{\text {perAC }}$ is a parameter representing the aircraft estimated flight hours per year. $F H C$ is the cost per flight hour which herein is considered as $\$ 71.00$ (Ali \& McLoughlin, 2012). The annual savings for the operator resulting from increased heavy maintenance intervals are calculated as

$$
O p S_{m i_{\text {incr }}}=D T R_{p e r A C} \times O F S \times L D C,
$$

where $L D C$ is the aircraft leasing cost per day (assumed hypothetically herein as $\$ 20,000$ ) and $D T R_{\text {perAC }}$ is the annual 
downtime reduction per aircraft due to longer intervals and increased product reliability, calculated as the difference between the average downtime per year for a heavy check $A D T$ and the calculated downtime $C D T$ :

$$
D T R_{p e r A C}=(A D T-C D T)
$$

with the average downtime per year for a heavy check being calculated as

$$
A D T=N H C_{p e r A C / Y} \times M D T_{a v g / h c},
$$

where $N H C_{\text {perAC/Y }}$ is the number of heavy checks for each operator aircraft per year and $M D T_{a v g / h c}$ is one of the model's parameters representing the market average aircraft downtime for a heavy check of a specific aircraft model. The number of heavy checks per aircraft per year is expressed as

$$
N H C_{p e r A C / Y}=\frac{F H Y_{p e r A C}}{M M I_{a v g / h c}},
$$

where $M M I_{a v g / h c}$ is a parameter corresponding to the market average maintenance interval for a heavy check, considered as being 6000 flight hours in this study (Ali \& McLoughlin, 2012).

The calculated annual downtime $C D T$ is

$$
C D T=N N H C_{p e r A C / Y} \times M D T_{a v g / h c},
$$

where $N N H C_{\text {perAC/Y }}$ corresponds to the new number of heavy checks for each operator aircraft per year after the maintenance interval increase and is calculated as

$$
N N H C_{\text {perAC/Y }}=\frac{F H Y_{\text {perAC }}}{N M I_{h c}},
$$

with $N M I_{h c}$ representing the new increased maintenance interval for a heavy check, being calculated as

$$
N M I_{h c}=M M I_{a v g / h c}+M I I_{y e a r} .
$$

As previously mentioned, the proposed product-service collaboration business model delivers value to OEMs by enabling these companies to forecast more accurately spare parts demand, thus promoting significant cost reduction through more efficient inventory management.

As maintenance providers, MRO companies collect valuable information on spare parts consumption, since all data related to the aircraft parts replaced in each shop visit are recorded and stored in databases, allowing the accumulation of significant amounts of information on parts consumption along the years. According to the collaboration proposal presented in this research, data can be shared with OEMs, promoting identification of the most demanded parts per aircraft model and geographical area. This information enables OEMs to optimize their inventory levels, generating cost reductions.

A case study developed by an aerospace OEM and published by the SAS Institute discusses potential gains that can be obtained with enhanced parts demand forecasting (SAS, 2014). This study reports that a manufacturer was able to increase significantly the accuracy of forecasting and consequently reduce inventory costs by automating statistical analysis of in-service data. The return over investment after one year was estimated to be within the range of \$10-15 million.

Another study (Cohen \& Wille, 2006) also quantifies gains derived from parts inventory optimization promoted by better consumption forecasting as a result of historical data analysis. In that research is mentioned an inventory cost reduction of $\$ 1$ million per aircraft over ten years, representing an annual reduction of $\$ 100,000$ per aircraft.

Therefore, in order to model the relation between the amount of in-service data and the inventory cost reduction, this research proposes to use the parameters reported in Cohen and Wille (2006) and SAS (2014) combined with the ones in Canaday (2016), which reports that 240 aircrafts in four years produced reasonable amounts of in-service data to enable conclusive statistical analysis, to build up the assumption that 480 heavy checks (considering each aircraft has one heavy check every two years) would produce sufficient data to promote annual inventory gains of the order of $\$ 10$ million. Moreover, considering the business model where MRO companies will share maintenance data with OEMs, the annual savings due to inventory cost reduction for OEMs are directly proportional to the number of heavy checks performed by MRO companies for a specific aircraft type:

$$
I S_{O E M}=(10,000,000) \times\left(\frac{N H C_{\text {year }}}{480}\right),
$$

while the positive impact on an OEM's gross profit is calculated by

$$
I G P_{O E M_{i n v}}=\frac{I S_{O E M}}{G P_{O E M}} .
$$

\section{Qualified Technical Personnel}

MRO providers depend on a skilled technical labor force to produce good-quality and efficient maintenance services. Therefore, the amount of technical training given to technicians is herein considered to be one of the key operational resources for a smooth MRO operation, as it directly affects TAT. Examples of technical training include:

- aircraft model specific: the MRO firm must have all the technicians trained in all the aircraft models for which it is certified to work on;

- special services: such as nondestructive inspection (eddy current, x-ray, dye penetrant, magnetic particle, ultrasound), borescope inspections;

- standard maintenance practices. 
There are other types of non-technical training, which might not affect productivity directly, but are usually given to MRO company employees. Some examples are: aviation regulations; lean manufacturing; language courses; customer relations; safety management system; human factors; etc.

A study conducted by Dinero (2005) in the aerospace company Northrop Aircraft Inc. demonstrates many positive results that were achieved plant wide after consistent training of 1241 employees. The results were: production increase of $17 \%$; break-in time to train a person on a new job reduced by $22 \%$; rejections reduced by $12 \%$; scrap reduced by $27 \%$; injuries reduced by $45 \%$.

The model presented here uses the production increase data from Dinero (2005) to establish the relation between investment in training and expected TAT gains:

$$
E T I_{t r}=\left(T I_{t r_{\text {avg }}}+I G_{t r}\right)
$$

with $T I_{t r_{\text {avg }}}$ representing the average TAT increase due to lack of training. The time increase $T I_{t r_{a v g}}$ is calculated as the optimum TAT (determined based on experience and benchmarking for when $100 \%$ resources are available) multiplied by $17 \%$ (this percentage represents the potential efficiency increase based on Northrop Aircraft Inc.'s case (Dinero, 2005)):

$$
T I_{t r_{\text {avg }}}=T A T_{\text {avg }}+0.17
$$

The investment gap in training $I G_{t r}$ is expressed as

$$
I G_{t r}=\frac{\left(I R_{t r}-I S_{O E M_{t r}}-I_{M R O_{t r}}\right)}{I R_{t r}}
$$

where $I R_{t r}$ represents the required investment in training by the MRO company in order to achieve optimal productivity and $I S_{O E M_{t r}}$ is the investment shared by the OEM with the MRO company. $I_{M R O_{t r}}$ is the actual investment in training made by the MRO company. In summary, according to this rationale, the smaller the investment gap, the lower the risk of TAT delay due to lack of training.

The model presented here supports the financial feasibility assessment process of the proposed collaborative PSS by analyzing the impact on gross profit of both stakeholders created by related costs and investments. In that sense, OEM investment in MRO companies by providing financial incentives for training would cause a negative impact on the OEM's gross profit. On the other hand, that same investment would have a positive impact on the MRO company's gross profit as this company would be reducing expenditures related to training courses. Hence the model proposes to calculate the annual impact on an OEM's gross profit resulting from its investment in training $I G P_{O E M_{t r}}$ as

$$
I G P_{O E M_{t r}}=\frac{-I S_{O E M_{t r}}}{G P_{O E M}},
$$

where $G P_{O E M}$ is the OEM's annual gross profit (a parameter within the model that must be set in accordance with the size of the OEM).

The impact on an MRO firm's gross profit resulting from investment in training received from the OEM is

$$
I G P_{M R O_{t r}}=\frac{\left(-I_{M R O_{t r}}+I S_{O E M_{t r}}\right)}{G P_{M R O}},
$$

where $G P_{M R O}$ is the MRO firm's annual gross profit (also a parameter to be set in accordance with the size of the MRO company).

\section{Model Output}

\section{Gross Profit}

The total impact on an OEM's gross profit takes into account all the investments made in MRO firms as well as the gains obtained with in-service data collected from those maintenance providers. Thus, the final balance is given by

$$
\begin{gathered}
I G P_{O E M}=I G P_{O E M_{s p}}+I G P_{O E M_{t o}}+I G P_{O E M_{i n v}}+ \\
I G P_{O E M_{p d}}+I G P_{O E M_{t r}},
\end{gathered}
$$

where the indices $s p$, to, inv, $p d$, and $t r$ refer to spare parts, tooling, inventory, product data, and training, respectively.

The total impact on the MRO firm's gross profit resulting from investments received from the OEM is given by

$I G P_{M R O}=I G P_{M R O_{s p}}+I G P_{M R O_{t o}}+I G P_{M R O_{p d}}+I G P_{M R O_{t r}} \cdot(35)$

\section{Operator's Savings}

The proposed collaborative approach aims at adding value to operators as a result of two main reasons: 1) these companies will operate a more reliable aircraft, which will require less maintenance due to increased scheduled maintenance intervals; and 2) MRO enterprises will deliver more efficient services, being able to reduce the TAT of heavy checks, thus providing operators with reduced aircraft downtime.

As mentioned before, the variable $T O p S_{\text {isdata }}$ represents the financial gains produced by the reliability increase. Herein, $O p s_{r d t}$ defines the operator's cost savings promoted by reduced aircraft downtime during heavy checks, being calculated as follows:

$$
O p S_{r d t}=D T R_{A C} \times L D C \times N N H C_{p e r A C / Y} \times O F S,
$$

where $L D C$ is a parameter related to aircraft leasing cost per day. $D T R_{A C}$ is the downtime reduction per aircraft in days, and is formulated as a function of the resources availability level:

$$
D T R_{A C}=M D T_{h c}-\left(T A T_{o p t}+E T I\right),
$$

where the parameter $M D T_{h c}$ corresponds to the acceptable maintenance downtime for a heavy check as per market 
requirements. TAT $T_{o p t}$ is the parameter that specifies the optimal TAT that an MRO company is able to achieve if $100 \%$ of resources are available. This value can be estimated by an MRO expert. ETI represents the total expected TAT increase during a heavy check execution in the MRO company due to lack of resources, and is calculated as

$$
E T I=\max (A)+E T I_{t r}
$$

where

$$
\begin{gathered}
A=\left[E T I_{c p}, E T I_{l e p}, E T I_{h e p}, E T I_{r o t}, E T I_{N D I}, E T I_{h c}\right. \\
\left.E T I_{s t}, E T I_{t s}, E T I_{s i}, E T I_{i d}, E T I_{f d}, E T I_{c m m}, E T I_{s b}\right] .
\end{gathered}
$$

Therefore, the operator's total savings $T O p S$ is defined as

$$
T O p S=T O p S_{\text {isdata }}+O p S_{r d t} .
$$

\section{Limitations}

The presented model does not consider the possibility of MRO companies sharing a percentage of their revenue (generated by the collaborative approach) with OEMs, nor quantifies potential gains that a manufacturer could obtain as a result of strengthening its brand due to a stronger services network. Therefore, additional value can be generated to OEMs if these opportunities are considered. Research is required to develop mathematical relations that could describe how a stronger OEM brand could result in more sales and thus increased revenues.

It is also important to highlight that the presented model allows analysis of business models that involve only one type of aircraft and heavy check at a time. Therefore, future work is encouraged to enhance this model to account for multiple types of aircrafts and heavy checks.

The collaborative approach proposed herein between airframe OEMs and MRO enterprises could be extended to manufacturers of aerospace components and their respective independent service network. For instance, business relations between engine manufacturers and the related maintenance shops could be similarly mapped in a quantitative model to promote creation of collaborative partnerships. In summary, the concept of designing structured collaboration business models can be studied and applied to many other types of components such as landing gears, auxiliary power units, electronic modules, etc. However, the collaboration approach would make more sense for highvalue-added components due to the possibility of more significant savings with the cost-of-opportunity resulting from reduced maintenance TATs.

Emerging technologies such as additive manufacturing and artificial intelligence can be studied within the context of this research to address issues related to spare parts availability and troubleshooting time, respectively.
Moreover, this research identifies opportunity for further studies to develop mathematical models to describe how acquisition of in-service data can reduce maintenance intervals due to increased product reliability. This work describes such relations based on assumptions created from data published by Boeing and Airbus on reductions obtained in maintenance intervals due to increased product reliability and use of in-service data. A future study could be conducted within the broad area of big data analytics, which is gaining increasing attention in the aerospace industry.

\section{Concluding Remarks}

Motivated to resolve challenges faced by airframe OEMs, MRO firms, and operators, this paper proposes a quantitative model to support collaborative business approaches. In the context of this model, the reader shall understand collaboration as how OEMs and MRO firms can exchange product and in-service data, share risks, and split investments to deliver high-level services to operators. Further, the amount of investments made by OEMs or MRO companies in any of the required resources (i.e., product data, spare parts, tooling, or training) represents the level of financial collaboration from each company. The higher the total investments, the more maintenance capacity the MRO company will offer, thus the shorter will be aircraft downtime during heavy maintenance, meaning higher savings to operators.

The presented model has been built based on real information and knowledge that exists in an independent airframe MRO firm in South America and its interactions with different airframe OEMs. The main business dependencies between the two stakeholders have been mapped to formulate the relationships by which they exchange key operational resources. Additionally, the model has captured the financial implications on operators' revenue as a function of TAT variations, resulting from fluctuations of resources availability. Therefore, this quantitative model represents the main contribution of this research to the literature and is intended to aid OEMs and MRO companies with the assessment of business collaboration alternatives, where economic feasibility can be individually calculated for each player based on the balance between the amount of investments in operational resources and the financial returns for each company.

The presented model is exercised in Part II of this paper for different sets of parameter values, determined according to the characteristics of the involved companies, such as enterprise size, type of aircraft that comprise the operator's fleet, projected production capacity of the MRO firm, etc. For instance, the size of the required inventory will depend on the proposed production capacity of the MRO company, so the higher the desired capacity, the larger the required inventory; gross profit will vary with the size of the 
company; an operator's annual savings will depend on its fleet size and on the number of flight hours that each aircraft performs; the market average downtime for a heavy check depends on the type of aircraft being considered. Therefore, the companion paper will demonstrate the model, comparing results for two different combinations of companies: 1) a large OEM, a small MRO firm, and a small operator; and 2) a large OEM, a large MRO firm, and a large operator. We note that the quantitative collaborative model can also be used for optimal decisionmaking when considering more complex investment scenarios and increased number of resources or identification of partnerships that maximize the gross profit of OEMs and MRO companies as well as operators' savings.

\section{Acknowledgements}

The first author acknowledges CAPES, the Brazilian Foundation of the Ministry of Education, and McGill Faculty of Engineering Doctoral Award for providing the required financial support which enabled the development of this work.

\section{References}

Ali, K. M., \& McLoughlin, B. (2012). Benefits of optimizing maintenance intervals. 8th IATA Maintenance Cost Conference, Atlanta, GA.

Canaday, H. (2016). Big data: Finding the MRO nuggets. Aviation Week and Space Technology.

Cohen, M. A., \& Wille, J. H. (2006). Implications for service parts management in the rapidly changing aviation MRO market. Retrieved from http://opim.wharton.upenn.edu/fd/forum/pdf2006/mrocohenwille. pdf/

Darci, P. (2004). Program evaluation review technique: Critical path method. INDG.

Dinero, D. (2005). Training within industry: The foundation of lean, HAR/ COM edition. Oxford, UK: Productivity Press.

Federal Aviation Administration. (2013). Practices and perspectives in outsourcing aircraft maintenance. Office of Aviation Research DOT/ FAA/AR02/122.
Goncalves, C. D., \& Kokkolaras, M. (2015). Value-driven modelling of tactical and operational decisions in support of aerospace productservice systems design. International Design Engineering Technical Conferences and Computers and Information in Engineering Conference, Boston, MA, August 2-5, 2015, ASME, p. V02BT03A044. doi:10.1115/DETC2015-46965

Goncalves, C. D. \& Kokkolaras, M. (2017). Modelling the relationship between aviation original equipment manufacturers and maintenance, repair and overhaul enterprises from a product-service system perspective. Proceedings of the 21st International Conference on Engineering Design, Vancouver, Canada, August 21-15, 2017, ICED17, Vol. 3, pp. 389-398.

Lee, S. G., Ma, Y. S., Thimm, G. L., \& Verstraeten, J. (2008). Product lifecycle management in aviation maintenance, repair and overhaul. Computers in Industry, 59, 296-303.

McLoughlin, B., Doulatshahi, F., \& Onorati, J. (2011). Improving maintenance programs through statistical analysis. Boeing AeroMagazine.

PIPAME. (2010). Maintenance et réparation aéronautique. Retrieved from http://www.entreprises.gouv.fr/files/files/directions-services/etudes-etstatistiques/etudes/aeronautique-maintenance/aeronautique-maintenance. pdf

Rosenberg, B. (2004). Everybody's doing it; airline maintenance strategies are diverse, but all include an element of outsourcing. Aviation Week and Space Technology, 19 April, p. 68.

SAS. (2014). The power to know: How can we reduce inventory costs while increasing aircraft fleet readiness? Retrieved from https://www. sas.com/content/dam/sas/en-us/doc/solutionbrief/defense-andaerospace-reduce-inventory-costs-105547.pdf/

Vieira, D. R., \& Loures, P. L. (2016). Maintenance, repair and overhaul (MRO) fundamentals and strategies: An aeronautical industry overview. International Journal of Computer Applications, 135, 21-29.

Tegtmeier, L. A. (2013). Our biennial survey examining where the aircraft work goes. Aviation Week Inside MRO.

Dr. Michael Kokkolaras is Associate Professor in the Department of Mechanical Engineering at McGill University. His research interests include multidisciplinary optimization, simulation-based engineering design, and product-service systems.

Dr. Cassio Dias Goncalves has completed his doctoral studies under the supervision of Prof. Kokkolaras at McGill University and is now Maintenance Manager at Digex Aircraft Maintenance in Brazil. 